\title{
Anaerobic digestion performance of sweet potato vine and animal manure under wet, semi-dry, and dry conditions
}

\author{
Enlan Zhang ${ }^{1,2}$, Jiajia Li² ${ }^{*}$ Keqiang Zhang ${ }^{2}$, Feng Wang ${ }^{2}$, Houhua Yang ${ }^{2}$, Suli Zhi ${ }^{2}$ and Guangqing Liu ${ }^{1}$
}

\begin{abstract}
Sweet potato vine (SPV) is an abundant agricultural waste, which is easy to obtain at low cost and has the potential to produce clean energy via anaerobic digestion (AD). The main objectives of this study were to reveal methane production and process stability of SPV and the mixtures with animal manure under various total solid conditions, to verify synergetic effect in co-digestion of SPV and manure in AD systems, and to determine the kinetics characteristics during the full AD process. The results showed that SPV was desirable feedstock for AD with $200.22 \mathrm{~mL} / \mathrm{g} \mathrm{VS}$ added of methane yield in wet anaerobic digestion and $12.20 L_{\text {methane }} / L_{\text {working volume }}$ in dry anaerobic digestion (D-AD). Synergistic effects were found in semi-dry anaerobic digestion and D-AD with each two mixing feedstock. In contrast with SPV mono-digestion, co-digestion with manure increased methane yield within the range of $14.34-49.11 \%$ in different AD digesters. The values of final volatile fatty acids to total alkalinity (TA) were below 0.4 and the values of final pH were within the range of 7.4-8.2 in all the reactors, which supported a positive relationship between carbohydrate hydrolysis and methanogenesis during AD process. The mathematical modified first order model was applied to estimate substrate biodegradability and methane production potential well with conversion constant ranged from 0.0003 to 0.0953 1/day, which indicated that co-digestion increased hydrolysis efficiency and metabolic activity. This work provides useful information to improve the utilization and stability of digestion using SPV and livestock or poultry manure as substrates.
\end{abstract}

Keywords: Sweet potato vine, Animal manure, Total solid, Co-digestion, Process stability

\section{Introduction}

Total solid (TS) concentration is one of the most important parameters in the efficiency assessment of anaerobic digestion. It is widely accepted including wet, semi-dry, and dry anaerobic digestion, when TS of substrate are $<10,10-15$, or $>15 \%$, respectively ( $\mathrm{Li}$ et al. 2011; Liotta et al. 2015). Wet anaerobic digestion (W-AD) is widely applied to treat livestock and poultry breeding wastewater, food waste and energy crop due to high methane yield per unit substrate, low level of sludge generation and convenient operation and maintenance

\footnotetext{
*Correspondence: lijiajia_caas@hotmail.com

${ }^{2}$ Innovation Team of Animal Husbandry Pollution Prevention and Control, Agro-Environmental Protection Institute, Chinese Academy of Agricultural Sciences, 504 Zonghe Building, No.31 Fukang Road, Nankai District, Tianjin 300191, People's Republic of China

Full list of author information is available at the end of the article
}

(Zhang et al. 2000; Demirel and Scherer 2009; Nagao et al. 2012). However, for feedstock with low moisture content, such as crop straw and municipal sludge, dry anaerobic digestion (D-AD) is a better choice because of low consumption of water, small reactor requirement and high volumetric methane production (Guendouz et al. 2010; Brown and Li 2013). In addition, the storage and recovery of anaerobic sludge activity has aroused the concern of researchers (Li et al. 2014), which help to solve the demand for large amounts of activated sludge and accelerate the start-up of D-AD reactors.

Traditionally, animal manure was used as mono-substrate to produce renewable biogas in most of the digesters around the world (Wu et al. 2010). However, the deficiency of carbon may hinder the biodegradability of substrate and decrease the methane yield. Compared with mono-substrate digestion, co-digestion has many 
benefits including dilution of potential toxic compounds, synergistic effects of microorganisms, improved balance of nutrients, increased digestion rate and better biogas yield (Sosnowski et al. 2003; Cuetos et al. 2011). Many studies have been reported on anaerobic co-digestion with crop stalk and animal manure (Søndergaard et al. 2015; Awais et al. 2016; Hassan et al. 2017). The substrate selection for co-digestion depends from the amount of feedstock and the cost of collection and transportation (Asam et al. 2011). Sweet potato vine (SPV) and animal manure are typical agricultural wastes in the world, especially in China. The annual production of animal manure has exceeded 2.1 billion tons since 2011 in China (Zhu and Ma 2014). Meanwhile, 106.64 million tons of sweet potato was harvested in 2015 (National Bureau of Statistics of China 2016), which was 53.32 million tons of fresh SPV calculated by the shoot-root ratio of 0.5. So far, there is no literature on the evaluation of methane productivity and operation stability of SPV alone and codigestion from SPV and animal manure in W-AD, semidry anaerobic digestion (SD-AD) or D-AD systems.

The objectives of the present study were to: (1) investigate the methane yield, volumetric methane productivity and process stability during the digestion of SPV and the mixtures with animal manure; (2) verify the synergetic effect in the co-digestion system under various TS conditions; (3) determine the dynamical features using modified first order model during the full AD process.

\section{Methods}

\section{Substrates and inoculum}

Fresh dairy manure (DM), chicken manure (CM) and pig manure (PM) were obtained from large-scale farms in
Binhai New District and Ninghe District, Tianjin, China. Sweet potato vine (SPV) was collected in Changping District, Beijing, China. SPV was dried in air for 1 week and then smashed to 20 meshes by a mill (Taisite, China). Inoculum used in this study was activated sludge from a running anaerobic digester treating pig manure, which locates in Xiqing District, Tianjin, China. Before utilization, inoculum was passed a $2 \mathrm{~mm}$ sieve to separate and discard large particles and then partially pre-concentrated by a centrifuge (Xiangyi, China). The characteristics of substrates and inoculum are presented in Table 1.

\section{Test setup}

Batch AD tests were carried out in triplicate using 1 L Duran glass bottles with a working volume of $0.5 \mathrm{~L}$ at $37^{\circ} \mathrm{C}$ in an incubate room. TS is made up of volatile solid (VS) and ash, and only VS can be degraded and converted into methane. To improve the evaluation accuracy of volumetric methane productivities and unit substrate utilization efficiency, calculation based on VS was used in this study. The initial organic loading (OL) for W-AD, SD-AD and D-AD was 30, 60 and $90 \mathrm{~g}-\mathrm{VS} / \mathrm{L}$, respectively. The substrate to inoculum (S/I) ratio of each digester was 3 on VS basis. Substrates were mixed with tap water and inoculum, and the final TS were $5.49-6.93 \%$ for W-AD; $10.49-13.36 \%$ for SD-AD; and $15.73-20.04 \%$ for $\mathrm{D}-\mathrm{AD}$ (Table 2). All treatments were conducted at the same time including mono-digestion of SPV or animal manure and co-digestion of SPV and manure at 1:1 ratio on VS basis. The digesters were tightly closed with rubber stopper and screw caps, and then argon gas was used to purge the headspace of digesters to ensure an initial anaerobic environment. Inoculum and tap water without

Table 1 Characteristics of substrates and inoculum

\begin{tabular}{|c|c|c|c|c|c|c|}
\hline Parameter & SPV & DM & PM & $\mathrm{CM}$ & OS & CS \\
\hline TS $(\%)^{a}$ & $91.8 \pm 0.7$ & $20.2 \pm 0.1$ & $31.6 \pm 0.2$ & $28.2 \pm 0.3$ & $3.8 \pm 0.0$ & $20.7 \pm 0.6$ \\
\hline VS (\%) ${ }^{\mathrm{a}}$ & $78.7 \pm 0.9$ & $17.0 \pm 0.4$ & $24.2 \pm 0.3$ & $17.3 \pm 0.3$ & $2.0 \pm 0.1$ & $11.6 \pm 0.5$ \\
\hline VS/TS (\%) & $85.7 \pm 0.4$ & $83.9 \pm 1.6$ & $76.5 \pm 0.8$ & $61.4 \pm 0.7$ & $52.6 \pm 1.3$ & $56.1 \pm 0.5$ \\
\hline$C(\%)^{b}$ & $41.4 \pm 1.0$ & $43.5 \pm 0.2$ & $40.0 \pm 0.1$ & $31.4 \pm 0.8$ & $30.1 \pm 0.9$ & $30.1 \pm 0.9$ \\
\hline$H(\%)^{b}$ & $5.0 \pm 0.2$ & $6.0 \pm 0.4$ & $5.5 \pm 0.5$ & $4.3 \pm 0.3$ & $4.3 \pm 0.2$ & $4.3 \pm 0.2$ \\
\hline$N(\%)^{b}$ & $2.7 \pm 0.0$ & $2.7 \pm 0.2$ & $3.6 \pm 0.1$ & $4.1 \pm 0.1$ & $4.0 \pm 0.1$ & $4.0 \pm 0.1$ \\
\hline $\mathrm{C} / \mathrm{N}$ & $15.1 \pm 0.6$ & $16.1 \pm 1.2$ & $11.2 \pm 0.4$ & $7.7 \pm 0.1$ & $7.5 \pm 0.0$ & $7.5 \pm 0.0$ \\
\hline $\mathrm{pH}$ & ND & $8.2 \pm 0.1$ & $6.5 \pm 0.0$ & $7.2 \pm 0.0$ & $8.1 \pm 0.0$ & $8.8 \pm 0.0$ \\
\hline $\mathrm{TA}(\mathrm{mg} \mathrm{CaCO} / \mathrm{g})^{\mathrm{b}}$ & ND & $33.4 \pm 0.2$ & $65.5 \pm 3.4$ & $53.0 \pm 1.6$ & $5.7 \pm 0.0$ & $24.7 \pm 0.4$ \\
\hline $\operatorname{VFAs}(\mathrm{g} / \mathrm{kg})^{\mathrm{b}}$ & $0.1 \pm 0.0$ & $0.1 \pm 0.0$ & $2.0 \pm 0.2$ & $0.5 \pm 0.1$ & $0.2 \pm 0.0$ & $0.2 \pm 0.0$ \\
\hline TAN $(\mathrm{mg} / \mathrm{g})^{\mathrm{b}}$ & ND & $2.4 \pm 0.0$ & $12.1 \pm 0.5$ & $5.5 \pm 0.1$ & ND & ND \\
\hline
\end{tabular}

ND, not determined; SPV, sweet potato vine; DM, dairy manure; PM, pig manure; CM, chicken manure; OS, original sludge; CS, centrifuged sludge; TS: total solid; VS: volatile solid; TA, total alkalinity; VFAs, volatile fatty acid; TAN, total ammonia-nitrogen

a As total weight of sample

b As TS of sample 
Table 2 The initial operating parameters of the anaerobic reactors

\begin{tabular}{|c|c|c|c|c|c|c|}
\hline \multirow[t]{2}{*}{ Samples } & \multicolumn{2}{|l|}{ W-AD } & \multicolumn{2}{|l|}{ SD-AD } & \multicolumn{2}{|l|}{ D-AD } \\
\hline & OL (g-VS/L) & TS (\%) & OL (g-VS/L) & TS (\%) & OL (g-VS/L) & TS (\%) \\
\hline SPV & 30 & 5.49 & 60 & 10.49 & 90 & 15.73 \\
\hline DM & 30 & 5.55 & 60 & 10.59 & 90 & 15.89 \\
\hline$S P V+D M$ & 30 & 5.52 & 60 & 10.54 & 90 & 15.81 \\
\hline PM & 30 & 5.94 & 60 & 11.38 & 90 & 17.07 \\
\hline$S P V+P M$ & 30 & 5.72 & 60 & 10.93 & 90 & 16.40 \\
\hline $\mathrm{CM}$ & 30 & 6.93 & 60 & 13.36 & 90 & 20.04 \\
\hline $\mathrm{SPV}+\mathrm{CM}$ & 30 & 6.21 & 60 & 11.92 & 90 & 17.88 \\
\hline
\end{tabular}

$\mathrm{OL}$, organic loading; VS, volatile solid; TS, total solid

any substrate addition was used as blank to correct the methane yield. Each digester was shaken manually twice a day for $30 \mathrm{~s}$. The total digestion time of each digester was 40 days.

\section{Analytical methods}

TS and VS were measured by using standard methods described in APHA (2005). Elemental compositions of substrates were determined with an elemental analyzer (Vario EL cube, Germany). pH value was measured with a Delta $320 \mathrm{pH}$ electrode (Mettler Toledo, USA). Total alkalinity (TA) value was determined using ET 18 alkalimeter (Mettler Toledo, USA) with $0.1 \mathrm{~mol} / \mathrm{L}$ of $\mathrm{HCl}$ solution as neutralizer. Total ammonia-nitrogen (TAN) concentration was analyzed using Kjeldahl determination with semi-automatic Kjeldahl apparatus (Ketuo, China). Free ammonia (FA) concentration in the liquid was calculated from TAN concentration according to the following formula (1) (Rajagopal et al. 2013):

$$
F A=T A N \times\left(1+\frac{10^{-p H}}{10^{-\left(0.09018+\frac{2729.92}{T(K)}\right)}}\right)^{-1}
$$

where $\mathrm{T}$ represents the absolute temperature and $\mathrm{pH}$ is the final $\mathrm{pH}$ of sample.

The pressure in the bottle headspace was measured by a pressure gauge (WAL Mess-und Regelsysteme GmbH, Germany) at $37^{\circ} \mathrm{C}$ under atmospheric pressure by inserting the syringe needle through the robber stopper. After the biogas in the headspace was released, the pressure was measured again. The following formula (2) was used to calculate the biogas yield (ElMashad and Zhang 2010):

$$
V_{\text {biogas }}=\Delta P \times V_{\text {head }} \times C /(R \times T)
$$

where $V_{\text {biogas }}$ refers to daily biogas volume $(\mathrm{mL}), \Delta P$ means absolute pressure different (mbar), $V_{\text {head }}$ represents volume of the head space $(\mathrm{mL}), C$ stands for molar volume $(22.41 \mathrm{~L} / \mathrm{mol}), T$ is absolute temperature $(\mathrm{K})$, and
$\mathrm{R}$ represents universal gas constant (83.14 L/mbar/K/ $\mathrm{mol}$ ).

Biogas composition was measured using gas chromatography (Thermo Fisher, USA) with automatic sampler as described by Li et al. (2014). Volatile fatty acids (VFAs) in digestate were determined by gas chromatography (Thermo Fisher, USA) with automatic sampler as described by Song et al. (2016).

\section{Kinetic modeling}

The mathematical modified first order model (3) (Vavilin et al. 2008), which includes parameters for ultimate methane yield and conversion constant, has been widely applied in simulating the entire $\mathrm{AD}$ process (Zhao et al. 2016).

$$
Y=Y_{0}[(1-\beta)-(1-\beta) \exp (-\kappa t)]
$$

where $\mathrm{Y}$ refers to the cumulative methane yield $(\mathrm{mL} / \mathrm{g}$ $\left.\mathrm{VS}_{\text {added }}\right), \mathrm{Y}_{0}$ is the ultimate methane yield $\left(\mathrm{mL} / \mathrm{g} \mathrm{VS}_{\text {added }}\right)$, $\beta$ represents the non-degradable fraction of the substrate, $\kappa$ stands for the rate constant (1/day), and $t$ refers to the digestion time (day).

\section{Statistical analysis}

All the experimental data in this study was analyzed statistically using one way analysis of variance (ANOVA) with IBM SPSS Statistics 22 (IBM, USA). To conduct pairwise comparisons of the average of each studied parameter, the Fisher Least Significant Difference (LSD) was calculated at $\alpha=0.01$ and $\alpha=0.05$ (Zhang et al. 2007).

\section{Results}

\section{Characterization of substrates and inoculum}

The characterization of substrates and inoculum are shown in Table 1. SPV contained higher TS and VS content than manure. The VS/TS ratio of SPV, DM, PM, and CM were $85.7,83.9,76.5$ and $61.4 \%$, respectively. The ratio of $\mathrm{C} / \mathrm{N}$ of 
CM was determined to be 7.7 , which was the lowest one in four types of feedstock. PM contained the highest TA and TAN concentration among animal manure.

\section{Daily methane production performance}

The daily methane yield of SPV, animal manure and their mixtures under W-AD, SD-AD and D-AD are shown in Fig. 1. The methane production started immediately, and similar trends were observed for combinations of SPV and manure in W-AD systems. Anaerobic digestion of SPV alone showed significantly $(p<0.05)$ increase of daily methane yield in W-AD than in SD-AD and D-AD in the first 2 weeks. The highest daily methane yields of monodigestion of SPV were 33.08, 10.33 and $6.39 \mathrm{~mL} / \mathrm{g} \mathrm{VS}$ added in $\mathrm{W}-\mathrm{AD}, \mathrm{SD}-\mathrm{AD}$ and $\mathrm{D}-\mathrm{AD}$, respectively. In monodigestion treatments of animal manure, all the peaks of daily methane yield were obtained from day 4 to day 7. The highest daily methane yield of DM, PM and CM alone were 19.91, 27.57 and $26.37 \mathrm{~mL} / \mathrm{g} \mathrm{VS}_{\text {added }}$ in W-AD;
19.19, 21.00 and $16.39 \mathrm{~mL} / \mathrm{g} \mathrm{VS}_{\text {added }}$ in SD-AD; 15.38, 9.50 and $5.79 \mathrm{~mL} / \mathrm{g} \mathrm{VS}_{\text {added }}$ in D-AD, respectively. Compared four types of substrates, the changes of TS concentration had the least effect to daily methane production performance of DM.

For co-digestion of SPV with DM, PM and CM, the highest daily methane yields were 28.08, 30.38 and $28.95 \mathrm{~mL} / \mathrm{g} \mathrm{VS}_{\text {added }}$ in W-AD; 29.62, 18.14 and $13.86 \mathrm{~mL} / \mathrm{g}$ $\mathrm{VS}_{\text {added }}$ in SD-AD; 21.67, 12.55 and $10.39 \mathrm{~mL} / \mathrm{g} \mathrm{VS}_{\text {added }}$ in $\mathrm{D}$-AD, respectively. The results showed that co-digestion increased the daily methane yield of manure under the same state. As TS concentration was over $10 \%$, similar trends were found that the decrease of the daily methane yield in SPV+DM digesters was far less than in SPV+PM and SPV+CM systems.

\section{Comparison of methane yield and productivity}

Figure 2 shows the cumulative methane yield of SPV, animal manure and their mixtures under different TS
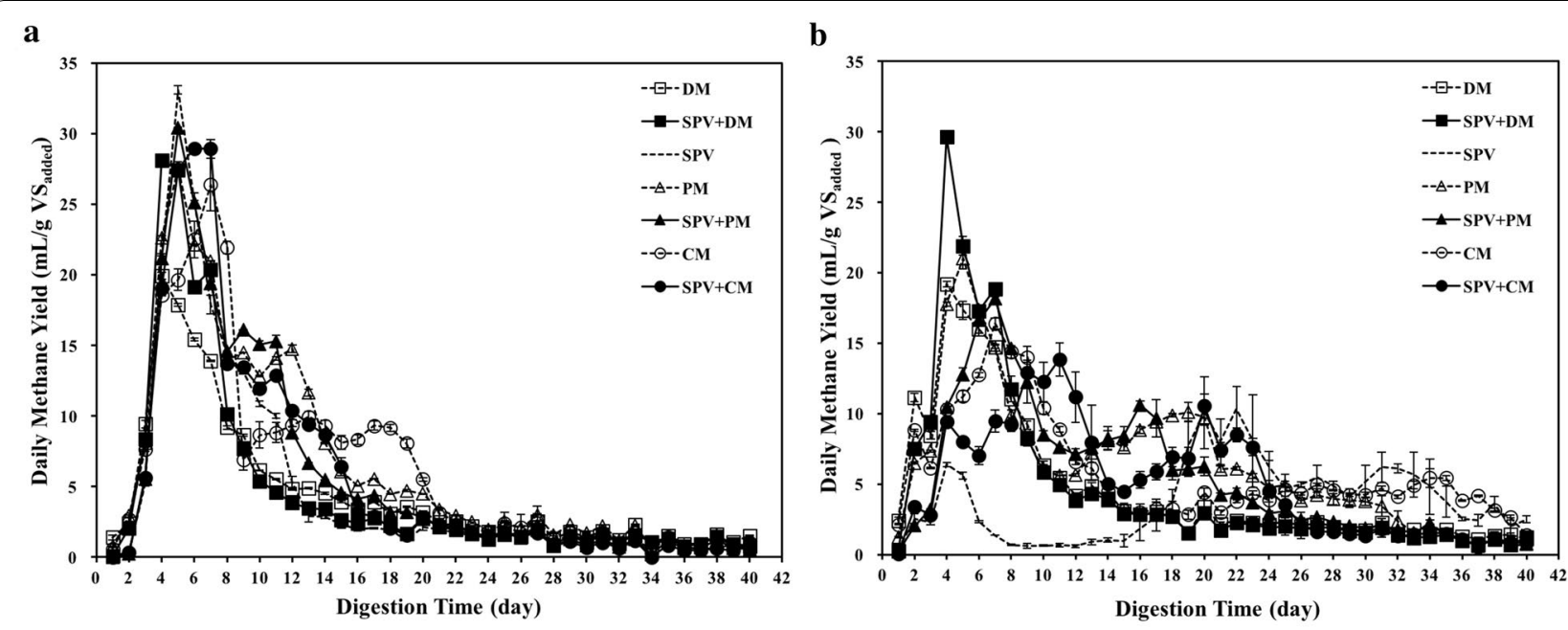

C

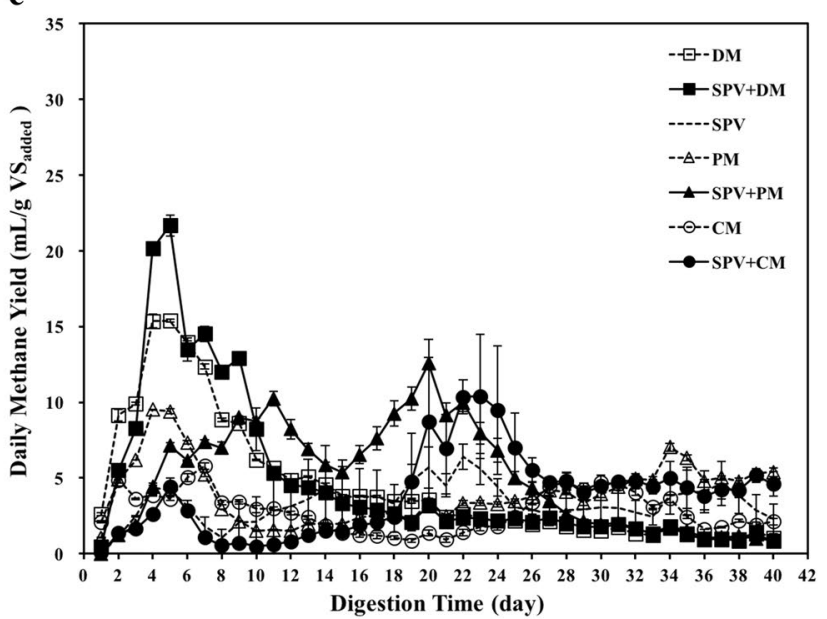

Fig. 1 Daily methane production performance from SPV and the mixtures with animal manure in $\mathbf{a} W-A D, \mathbf{b} S D-A D$ and $\mathbf{c} D-A D$ systems 
conditions. Almost $90 \%$ of the experimental methane yields were obtained after 28,35 and 37 days in W-AD, SD-AD and D-AD, respectively (Fig. $2 a-c$ ). In the first 2 weeks, fermentation suppressions were obviously found for SPV in SD-AD and D-AD. The cumulative methane yields of mono-digestion of SPV were 155.69 and $135.51 \mathrm{~mL} / \mathrm{g} \mathrm{VS}_{\text {added }}$ in SD-AD and D-AD, which were 77.77 and $67.68 \%$ of the yield in W-AD, respectively. In view of feedstock characterization, mono-digestion of SPV obtained significantly $(p<0.05)$ higher methane yield than $\mathrm{DM}$ in $\mathrm{W}-\mathrm{AD}$, but lower yield $(p<0.01)$ than animal manure in SD-AD. In W-AD and SD-AD, monodigestion with $\mathrm{PM}$ represented the highest methane yield, which was 261.88 and $258.02 \mathrm{~mL} / \mathrm{g} \mathrm{VS}_{\text {added }}$, respectively. In D-AD, co-digestion from SPV and PM obtained the methane peak at $202.06 \mathrm{~mL} / \mathrm{g} \mathrm{VS}_{\text {added }}$.

As revealed in Fig. 2d, the results indicated that total solid had negative effect on substrate utilization, especially in mono-digestion reactors. Compared to W-AD treatments, the cumulative methane yields of SD-AD and D-AD were reduced by $1.17-55.34 \%$. However, codigestion improved the methane production of substrate per unit, especially for SPV+DM. In comparison with SPV under the same TS condition, manure addition had an increase of methane yield with $14.34-49.11 \%$ except $\mathrm{SPV}+\mathrm{DM}$ in W-AD.

Figure 3 shows the comparison of volumetric methane productivities (VMP) in $\mathrm{W}-\mathrm{AD}, \mathrm{SD}-\mathrm{AD}$ and $\mathrm{D}-\mathrm{AD}$ reactors. All of digesters in $\mathrm{D}$ - AD showed higher VMP than in W-AD and SD-AD, except PM and CM mono-digestion. The volumetric methane yields were $5.36-7.86 \mathrm{~L}_{\text {methane }} /$ $\mathrm{L}_{\text {working volume }}$ in $\mathrm{W}-\mathrm{AD}$; 9.34-15.48 $\mathrm{L}_{\text {methane }} / \mathrm{L}_{\text {working volume }}$ in SD-AD; $10.19-18.19 \mathrm{~L}_{\text {methane }} / \mathrm{L}_{\text {working volume }}$ in D-AD, respectively. D-AD improved volumetric methane productivities by $55.52-109.83 \%$ of W-AD, whereas SD-AD increased VMP by $33.98-202.83 \%$ of W-AD.

\section{Synergistic effect of co-digestion}

Synergistic effect could be seen as an additional methane yield for co-digestion over the weighted average of
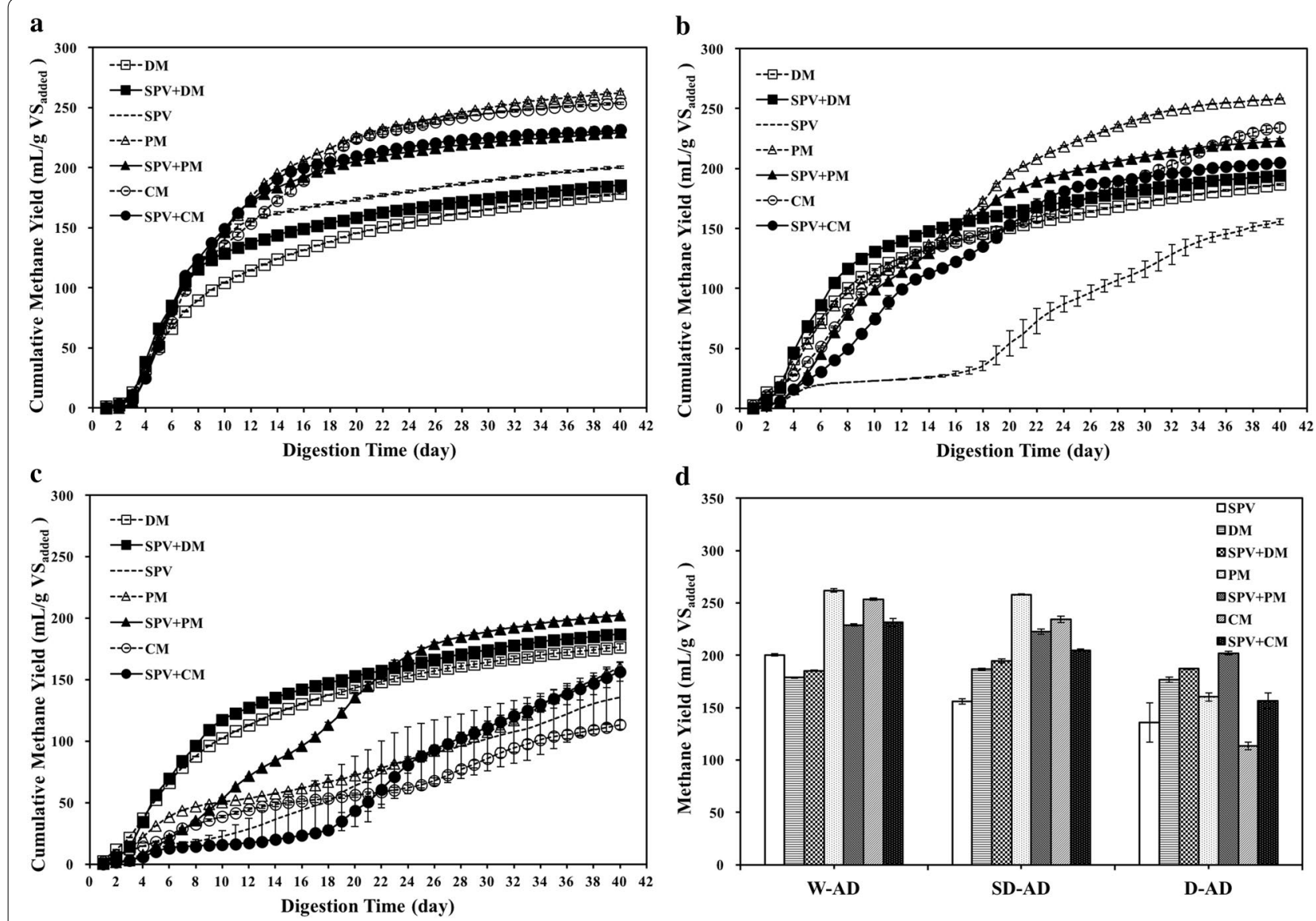

Fig. 2 Comparison of cumulative methane yield from SPV and the mixtures with animal manure in a W-AD, b SD-AD, $\mathbf{c} D-A D$ and $\mathbf{d}$ comparison of methane yield systems 


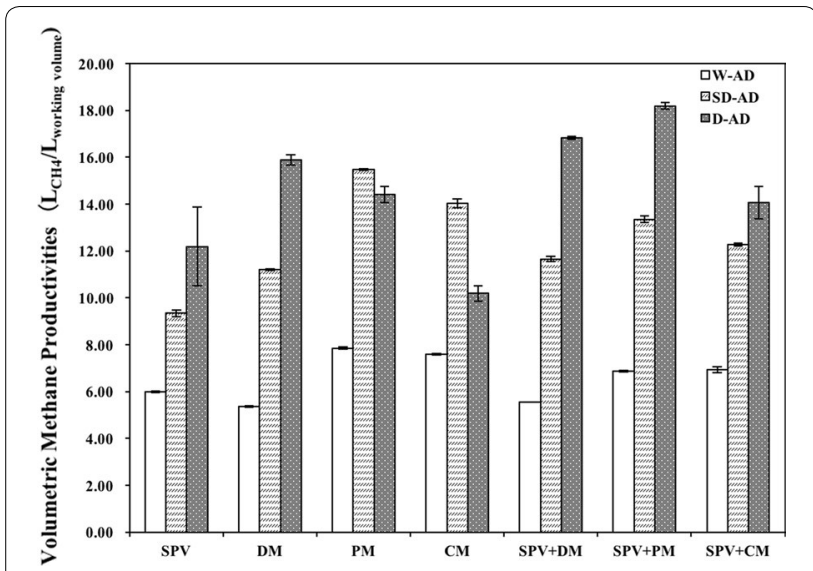

Fig. 3 Comparison of volumetric methane productivities from different mixtures of SPV and animal manure under W-AD, SD-AD and D-AD conditions the individual methane yield of each feedstock (Esposito et al. 2012). Weighted experimental methane yield (weighted EMY) was calculated as follows (4):

$$
\text { Weighted } \mathrm{EMY}=\mathrm{EMY}_{\mathrm{SPV}} \times 0.5+\mathrm{EMY}_{\text {manure }} \times 0.5
$$

where Weighted EMY refers to the weighted average of experimental methane yield for co-substrates, $\mathrm{EMY}_{\mathrm{SPV}}$ and $E M Y_{\text {manure }}$ stand for the experimental methane yield for SPV and animal manure, respectively.

If the difference (EMY-the standard deviation absolute value) was bigger than Weighted EMY, synergistic effect was confirmed to be available. The evaluation of synergistic effect on different condition of digestions was represented in Fig. 4. Synergistic effect was confirmed in co-digestion of SPV and three types of manure in SD-AD and D-AD. Manure addition improved methane yield by 13.53 and $19.85 \%$ of weighted TMY for DM, 7.62 and
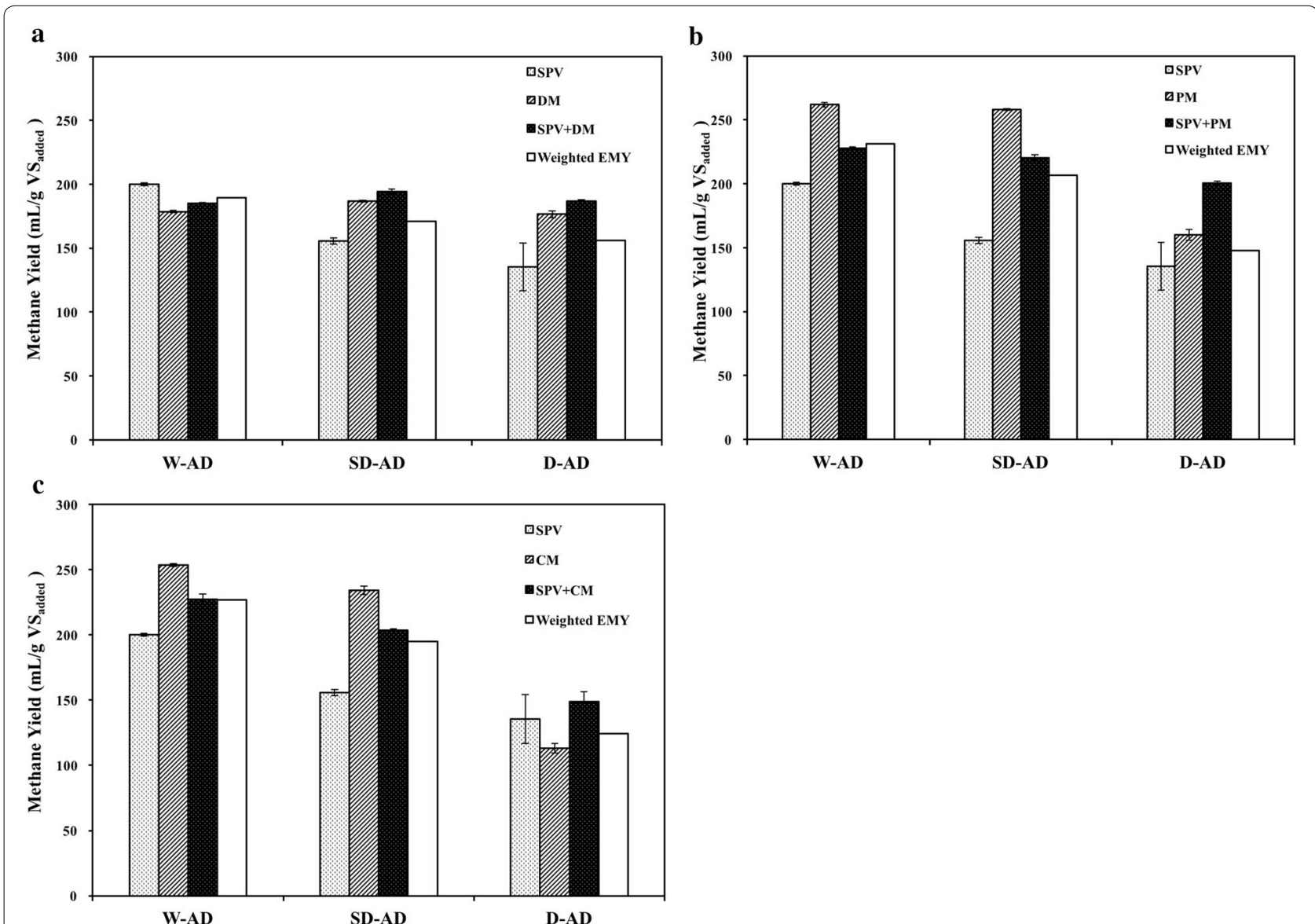

Fig. 4 Evaluation of synergistic effect of co-digestion with SPV and animal manure under various total solid conditions. a SPV+DM, b SPV+PM, c $\mathrm{SPV}+\mathrm{CM}$ 
$36.69 \%$ for $\mathrm{PM}, 5.09$ and $25.71 \%$ for CM, respectively. Therefore, co-digestion of SPV and manure under SD-AD or $\mathrm{D}-\mathrm{AD}$ is a recommendable way to produce biogas with small reactor volume.

\section{Evaluation of process stability in wet, semi-dry and dry digestion}

Imbalances of hydrolytic bacteria, acetogenic bacteria and methanogenic archaea may decrease methane productivity, even fail the fermentation. Usually, VFAs accumulation and ammonia inhibition are the significant factors to bring process stability down. The parameters of process stability for all the treatments are shown in Table 3.

The value of $\mathrm{pH}$ is often considered as an important and accessible criterion to evaluate AD stability. The reactors in this study showed the final $\mathrm{pH}$ value within the range of 7.4-8.2, which indicated an acceptable performance under various TS conditions, especially for D-AD (Lay et al. 1997; Weiland 2010). Usually, the ratio of VFAs to TA is a complementary parameter to judge whether methanogenic archaea was restrained in AD reactors. As seen in Table 3, generally, with the total solid increasing, the TA value highlighted rising trends. In the same type of reactors with similar TS concentration, the TA value of chicken manure system and pig manure system were higher than dairy manure system, which was in keeping with the characteristics of materials as shown in Table 1. Although suppression phenomenon of methane production was found in the beginning of the digestion, especially in $\mathrm{D}-\mathrm{AD}$, there was no obvious VFAs accumulation found in the end of AD tests. The final VFAs concentration was in the range of $0.2-4.3 \mathrm{~g} / \mathrm{kg}$ in $\mathrm{D}-\mathrm{AD}$, which was higher and slight higher than in W-AD and SD-AD. The further consumption of VFAs during the later period of digestion broke down the inhibition aggravation of gas production, improved daily methane production (Fig. 1b, c), and resulted in a satisfactory volumetric methane

Table 3 Characterization of digestate from different mixtures of SPV and animal manure in various anaerobic conditions

\begin{tabular}{|c|c|c|c|c|c|c|}
\hline Samples & Final pH & Final TAN (mg/g) & Final FA (mg/kg) & Final VFAs $(g / k g)$ & Final TA $\left(\mathrm{mg} \mathrm{CaCO}_{3} / \mathrm{g}\right)$ & VFAs/TA \\
\hline \multicolumn{7}{|l|}{ W-AD } \\
\hline CK & $7.8 \pm 0.0$ & $1.1 \pm 0.1$ & $37.2 \pm 1.9$ & $0.1 \pm 0.0$ & $3.4 \pm 0.4$ & $0.0 \pm 0.0$ \\
\hline SPV & $7.9 \pm 0.0$ & $1.7 \pm 0.1$ & $67.6 \pm 2.7$ & $0.5 \pm 0.0$ & $8.7 \pm 0.4$ & $0.1 \pm 0.0$ \\
\hline DM & $7.8 \pm 0.0$ & $1.3 \pm 0.2$ & $41.4 \pm 7.5$ & $1.2 \pm 0.0$ & $7.4 \pm 0.1$ & $0.2 \pm 0.0$ \\
\hline $\mathrm{SPV}+\mathrm{DM}$ & $7.8 \pm 0.0$ & $1.4 \pm 0.1$ & $52.2 \pm 4.2$ & $0.1 \pm 0.0$ & $7.9 \pm 0.4$ & $0.0 \pm 0.0$ \\
\hline PM & $7.6 \pm 0.0$ & $1.8 \pm 0.7$ & $44.2 \pm 16.1$ & $0.3 \pm 0.0$ & $10.7 \pm 0.1$ & $0.0 \pm 0.0$ \\
\hline $\mathrm{SPV}+\mathrm{PM}$ & $7.6 \pm 0.0$ & $1.8 \pm 0.0$ & $39.3 \pm 0.2$ & $0.3 \pm 0.0$ & $9.0 \pm 0.4$ & $0.0 \pm 0.0$ \\
\hline $\mathrm{CM}$ & $7.8 \pm 0.0$ & $3.0 \pm 0.0$ & $113.7 \pm 0.8$ & $0.5 \pm 0.1$ & $13.0 \pm 0.1$ & $0.0 \pm 0.0$ \\
\hline $\mathrm{SPV}+\mathrm{CM}$ & $7.7 \pm 0.0$ & $2.3 \pm 0.1$ & $68.7 \pm 2.7$ & $1.4 \pm 0.1$ & $11.1 \pm 0.1$ & $0.1 \pm 0.0$ \\
\hline \multicolumn{7}{|l|}{ SD-AD } \\
\hline CK & $7.4 \pm 0.0$ & $0.7 \pm 0.2$ & $9.3 \pm 2.2$ & $0.1 \pm 0.0$ & $4.0 \pm 0.1$ & $0.0 \pm 0.0$ \\
\hline SPV & $7.7 \pm 0.0$ & $1.6 \pm 0.0$ & $42.0 \pm 0.7$ & $0.8 \pm 0.1$ & $10.6 \pm 0.1$ & $0.1 \pm 0.0$ \\
\hline DM & $7.3 \pm 0.0$ & $1.3 \pm 0.2$ & $14.7 \pm 1.9$ & $0.8 \pm 0.1$ & $10.0 \pm 0.1$ & $0.1 \pm 0.0$ \\
\hline $\mathrm{SPV}+\mathrm{DM}$ & $7.5 \pm 0.0$ & $1.6 \pm 0.1$ & $26.0 \pm 0.9$ & $2.6 \pm 0.2$ & $11.2 \pm 0.1$ & $0.2 \pm 0.0$ \\
\hline PM & $7.6 \pm 0.1$ & $2.9 \pm 0.0$ & $57.7 \pm 0.7$ & $0.7 \pm 0.1$ & $16.6 \pm 0.1$ & $0.0 \pm 0.0$ \\
\hline$S P V+P M$ & $7.8 \pm 0.0$ & $2.3 \pm 0.5$ & $73.3 \pm 17.4$ & $0.4 \pm 0.0$ & $15.1 \pm 0.1$ & $0.0 \pm 0.0$ \\
\hline $\mathrm{CM}$ & $8.1 \pm 0.0$ & $4.5 \pm 0.0$ & $306.1 \pm 0.6$ & $0.2 \pm 0.0$ & $22.7 \pm 0.1$ & $0.0 \pm 0.0$ \\
\hline $\mathrm{SPV}+\mathrm{CM}$ & $8.0 \pm 0.0$ & $3.4 \pm 0.0$ & $171.3 \pm 2.1$ & $1.3 \pm 0.1$ & $16.9 \pm 0.1$ & $0.1 \pm 0.0$ \\
\hline \multicolumn{7}{|l|}{$D-A D$} \\
\hline CK & $7.7 \pm 0.1$ & $1.4 \pm 0.1$ & $38.3 \pm 2.1$ & $0.2 \pm 0.0$ & $6.7 \pm 0.1$ & $0.0 \pm 0.0$ \\
\hline SPV & $7.9 \pm 0.0$ & $3.2 \pm 0.1$ & $139.7 \pm 2.7$ & $4.3 \pm 0.2$ & $17.9 \pm 0.3$ & $0.3 \pm 0.0$ \\
\hline $\mathrm{DM}$ & $7.4 \pm 0.0$ & $2.5 \pm 0.0$ & $37.3 \pm 0.2$ & $3.8 \pm 0.1$ & $15.9 \pm 0.0$ & $0.2 \pm 0.0$ \\
\hline $\mathrm{SPV}+\mathrm{DM}$ & $7.8 \pm 0.1$ & $2.4 \pm 0.6$ & $77.3 \pm 20.3$ & $2.3 \pm 0.1$ & $17.1 \pm 0.3$ & $0.1 \pm 0.0$ \\
\hline PM & $8.2 \pm 0.1$ & $4.9 \pm 0.1$ & $420.8 \pm 11.0$ & $0.8 \pm 0.1$ & $26.7 \pm 0.1$ & $0.0 \pm 0.0$ \\
\hline $\mathrm{SPV}+\mathrm{PM}$ & $7.9 \pm 0.1$ & $4.0 \pm 0.4$ & $187.9 \pm 18.3$ & $0.5 \pm 0.0$ & $23.5 \pm 1.0$ & $0.0 \pm 0.0$ \\
\hline $\mathrm{CM}$ & $8.1 \pm 0.1$ & $6.7 \pm 0.5$ & $444.1 \pm 32.9$ & $0.5 \pm 0.0$ & $30.3 \pm 0.2$ & $0.0 \pm 0.0$ \\
\hline $\mathrm{SPV}+\mathrm{CM}$ & $8.2 \pm 0.1$ & $4.9 \pm 0.1$ & $382.3 \pm 11.0$ & $1.8 \pm 0.2$ & $24.6 \pm 0.3$ & $0.1 \pm 0.0$ \\
\hline
\end{tabular}

CK, control treatment; SPV, sweet potato vine; DM, dairy manure; PM, pig manure; CM, chicken manure; W-AD, wet anaerobic digestion; SD-AD, semi-dry anaerobic digestion; D-AD, dry anaerobic digestion; TA, total alkalinity; TAN, total ammonia nitrogen; FA, free ammonia; VFAs, volatile fatty acids 
production (Fig. 3). Meanwhile, the values of VFAs to TA were very low because of low VFAs residual in the end of digestion. All the data of VFAs to TA was below 0.4 in different $\mathrm{AD}$ reactors, which supported a positive relationship between carbohydrate hydrolysis and methanogenesis (Li et al. 2013).

Although all of the treatments gained satisfied methane yield, low daily methane productivity lasted 2 weeks or more for SPV in SD-AD and D-AD, PM in D-AD, $\mathrm{CM}$ and SPV+CM in D-AD (Fig. 1b, c). Total ammonia-nitrogen (TAN) content could maintain $\mathrm{pH}$ value by contributing the alkalinity to the AD system. However, ammonia inhibition restrained the microbial metabolism, when the concentration reached $4.0 \mathrm{mg} / \mathrm{g}$ of TAN or $250 \mathrm{mg} / \mathrm{kg}$ of free ammonia (FA) in AD systems (Procházka et al. 2012; Bujoczek et al. 2000). In this study, methane productivity wasn't restricted when FA value was over $250 \mathrm{mg} / \mathrm{kg}$, but affected when over $380 \mathrm{mg} /$ $\mathrm{kg}$. Thus, a decrease of $32.44-55.34 \%$ was found for PM, $\mathrm{CM}$ and SPV+CM in D-AD. For SPV mono-digestion in $\mathrm{SD}-\mathrm{AD}$ and $\mathrm{D}-\mathrm{AD}$, the decline of methane yield (based on per unit VS) was most likely attributable to the rapid hydrolysis of carbohydrates in the initial phase of digestion and poor mass transfer capacity in high TS system, which weakened substrate conversion efficiency.

Briefly, the final VFAs/TA values could be a proper parameter to judge the success of $\mathrm{AD}$ or not. However, TAN and free ammonia would be more significant indicators to estimate the methane productivity in this study. These results effectively suggested that, in contrast with mono-digestion, co-digestion of SPV and manure balanced the relationship of microbial communities, improved process stability and enhanced the methane production performance under W-AD, SD-AD and $\mathrm{D}-\mathrm{AD}$ conditions.

\section{Modified first order model of methane production}

Table 4 summarize the results of fitting the modified first order model to digestion data obtained with SPV and animal manure under various TS conditions. The equation describes the conversion constant and methane production potential for the experimental results well with $R^{2}$ values within the range of $0.9715-0.9966$. The first order constant $(\kappa)$, as an indicator for substrate biodegradability, reflects the hydrolysis efficiency and metabolic activity. In this study, $K$ value in W-AD ranged from 0.0642 to 0.09611 /day, in SD-AD ranged from 0.0003 to 0.09531 day, and in D-AD ranged from 0.0003 to 0.0796 $1 /$ day, which was partial consistency with the earlier work reported by Brown et al. (2012). SPV co-digestion with animal manure could increase the $\kappa$ value, which indicated better degradation efficiency and methane yield. As the increasing of total solid, DM kept the $\kappa$ value more stable than PM and CM, which indicated DM with greater buffer ability to acid than other manure. Interestingly, regardless of substrate types and total solid concentration, obvious reduction of methane yield was found as $\kappa$ value was lower than $0.011 /$ day in batch test.

\section{Discussion}

In view of substrate utilization efficiency, the increase of TS concentration had the negative effect to methane production performance. Usually, there are a series of important parameters to evaluate the operation stability, including $\mathrm{pH}$, VFAs, TA and ammonia concentration (Callaghan et al. 2002; Weiland 2010). As shown in Table 3, suitable $\mathrm{pH}$ range and VFAs/TA ratio guaranteed gas production efficiency. However, methane productivity was restricted when FA value was over $380 \mathrm{mg} / \mathrm{kg}$ in the reactors, which was also supported by Bujoczek et al. (2000).

Table 4 Parameters of modified first order model from different mixtures of SPV and animal manure in various anaerobic conditions

\begin{tabular}{|c|c|c|c|c|c|c|}
\hline \multirow[t]{2}{*}{ Samples } & \multicolumn{2}{|l|}{ W-AD } & \multicolumn{2}{|l|}{ SD-AD } & \multicolumn{2}{|l|}{ D-AD } \\
\hline & $\kappa$ & $R^{2}$ & $\kappa$ & $R^{2}$ & $\kappa$ & $\mathrm{R}^{2}$ \\
\hline SPV & 0.0961 & 0.9799 & 0.0003 & 0.9764 & 0.0006 & 0.9963 \\
\hline $\mathrm{DM}$ & 0.0742 & 0.9936 & 0.0834 & 0.9934 & 0.0751 & 0.9966 \\
\hline$S P V+D M$ & 0.0996 & 0.9840 & 0.0953 & 0.9889 & 0.0796 & 0.9915 \\
\hline PM & 0.0717 & 0.9904 & 0.0394 & 0.9953 & 0.0031 & 0.9859 \\
\hline$S P V+P M$ & 0.0848 & 0.9839 & 0.0441 & 0.9908 & 0.0137 & 0.9846 \\
\hline $\mathrm{CM}$ & 0.0642 & 0.9899 & 0.0389 & 0.9924 & 0.0078 & 0.9880 \\
\hline $\mathrm{SPV}+\mathrm{CM}$ & 0.0866 & 0.9819 & 0.0326 & 0.9884 & 0.0003 & 0.9715 \\
\hline
\end{tabular}

SPV, sweet potato vine; $D M$, dairy manure; PM, pig manure; CM, chicken manure; W-AD, wet anaerobic digestion; SD-AD, semi-dry anaerobic digestion; D-AD, dry anaerobic digestion 
In this study, co-digestion increased the daily and cumulative methane yield of substrate, and similar result was found by Li et al. (2013). As TS concentration increased, similar trends were found that the decrease of the daily methane yield in SPV+DM digesters was far less than in SPV+PM and SPV+CM systems. Also, weighted EMY was confirmed that co-digestion improved the methane production efficiency, especially in SD-AD and $\mathrm{D}-\mathrm{AD}$. Fitting parameters calculated from the modified first order model were further proved co-digestion had better hydrolysis efficiency and metabolic activity.

In conclusion, the maximum methane yield and volumetric production of mono-digestion of SPV were $200.22 \mathrm{~mL} / \mathrm{g} \mathrm{VS}_{\text {added }}$ in W-AD and $12.20 \mathrm{~L}_{\text {methane }} / \mathrm{L}_{\text {working }}$ volume in D-AD. Compared with digestion of SPV as single substrate, co-digestion with manure increased methane yield and volumetric productivity within the range of 14.34-49.11\% under different AD conditions. The significant synergistic effects were found in SD-AD and D-AD reactors. FA value of $380 \mathrm{mg} / \mathrm{kg}$ was considered as an indicator to decrease process stability, whereas VFAs/TA and $\mathrm{pH}$ was in the acceptable range. The mathematical modified first order model was applied to estimate substrate biodegradability and methane production potential well with $R^{2}$ values within the range of $0.9715-0.9966$ and conversion constant ranged from 0.0003 to 0.0953 $1 /$ day. Co-digestion with SPV and manure improved $k$ value, whereas obvious methane reduction was found as $\kappa$ value was lower than $0.011 /$ day. These results offer useful information to future application of anaerobic digestion with SPV and manure as feedstock.

\section{Abbreviations \\ AD: anaerobic digestion; W-AD: wet anaerobic digestion; SD-AD: semi-dry anaerobic digestion; D-AD: dry anaerobic digestion; OS: original sludge; CS: centrifuged sludge; SPV: sweet potato vine; CM: chicken manure; DM: dairy manure; PM: pig manure; S/I ratio: substrate/inoculum ratio; TS: total solid; VS: volatile solid; OL: organic loading; TA: total alkalinity; TAN: total ammonia nitrogen; FA: free ammonia; VFAs: volatile fatty acids; EMY: experimental methane yield.}

\section{Authors' contributions \\ ELZ performed the experiments and analyzed the raw data. JJL conceived the study, designed the experiments and drafted the manuscript. GQL and KQZ participated in the design of the study. FW carried out the model analysis, and HHY and SLZ helped to perform the experiments. All authors read and approved the final manuscript.}

\section{Author details \\ ${ }^{1}$ Biomass Energy and Environmental Engineering Research Center, College of Chemical Engineering, Beijing University of Chemical Technology, Bei- jing 100029, China. ${ }^{2}$ Innovation Team of Animal Husbandry Pollution Preven- tion and Control, Agro-Environmental Protection Institute, Chinese Academy of Agricultural Sciences, 504 Zonghe Building, No.31 Fukang Road, Nankai District, Tianjin 300191, People's Republic of China.}

\section{Competing interests}

The authors declare that they have no competing interests.
Availability of data and materials

All data are fully available without restriction.

Ethics approval and consent to participate

No animal or human subjects were used in this work.

Funding

This research was supported by NSFC-China (No. 51508284) and MOHRSS Program-China (No. 2016-|xry-lj).

\section{Publisher's Note}

Springer Nature remains neutral with regard to jurisdictional claims in published maps and institutional affiliations.

Received: 15 December 2017 Accepted: 12 March 2018

Published online: 22 March 2018

\section{References}

APHA (2005) Standard methods for the examination of water and wastewater, 21st edn. American Public Health Association, Washington DC

Asam ZUZ, Poulsen TG, Nizami AS, Rafique R, Kiely G, Murphy JD (2011) How can we improve biomethane production per unit of feedstock in biogas plants? Appl Energy 88(6):2013-2018

Awais M, Alvarado-Morales M, Tsapekos P, Gulfraz M, Angelidaki I (2016) Methane production and kinetic modeling for co-digestion of manure with lignocellulosic residues. Energy Fuels 30(12):10516-10523

Brown D, Li Y (2013) Solid state anaerobic co-digestion of yard waste and food waste for biogas production. Bioresour Technol 127:275-280

Brown D, Shi J, Li Y (2012) Comparison of solid-state to liquid anaerobic digestion of lignocellulosic feedstocks for biogas production. Bioresour Technol 124:379-386

Bujoczek G, Oleszkiewicz J, Sparling R, Cenkowski S (2000) High solid anaerobic digestion of chicken manure. J Agric Eng Res 76(1):51-60

Callaghan FJ, Wase DAJ, Thayanithy K, Forster CF (2002) Continuous codigestion of cattle slurry with fruit and vegetable wastes and chicken manure. Biomass Bioenergy 22(1):71-77

Cuetos MJ, Fernández C, Gómez X, Morán A (2011) Anaerobic co-digestion of swine manure with energy crop residues. Biotechnol Bioprocess Eng 16(5):1044-1052

Demirel B, Scherer P (2009) Bio-methanization of energy crops through monodigestion for continuous production of renewable biogas. Renew Energy 34(12):2940-2945

Elmashad HM, Zhang RH (2010) Biogas production from co-digestion of dairy manure and food waste. Bioresour Technol 101(11):4021-4028

Esposito G, Frunzo L, Giordano A, Liotta F, Panico A, Pirozzi F (2012) Anaerobic co-digestion of organic wastes. Rev Environ Sci Biotechnol 11(4):325-341

Guendouz J, Buffière P, Cacho J, Carrère M, Delgenes JP (2010) Dry anaerobic digestion in batch mode: design and operation of a laboratory-scale, completely mixed reactor. Waste Manag 30(10):1768-1771

Hassan M, Ding W, Umar M, Rasool G (2017) Batch and semi-continuous anaerobic co-digestion of goose manure with alkali solubilized wheat straw: a case of carbon to nitrogen ratio and organic loading rate regression optimization. Bioresour Technol 230:24-32

Lay JJ, Li YY, Noike T, Endo J, Ishimoto S (1997) Analysis of environmental factors affecting methane production from high-solids organic waste. Water Sci Technol 36(6-7):493-500

Li YB, Park SY, Zhu JY (2011) Solid-state anaerobic digestion for methane production from organic waste. Renew Sustain Energy Rev 15:821-826

Li YQ, Zhang RH, Liu XY, Chen C, Xiao X, Feng L, He YF, Liu GQ (2013) Evaluating methane production from anaerobic mono- and co-digestion of kitchen waste, corn stover, and chicken manure. Energy Fuels 27:2085-2091

Li JJ, Zicari SM, Cui ZJ, Zhang RH (2014) Processing anaerobic sludge for extended storage as anaerobic digester inoculum. Bioresour Technol 166:201-210

Liotta F, Chatellier P, Esposito G, Fabbricino M, Frunzo L, van Hullebusch ED, Lens PNL, Pirozzi F (2015) Modified anaerobic digestion model no. 1 for 
dry and semi-dry anaerobic digestion of solid organic waste. Environ Technol 36(7):870-880

Nagao N, Tajima N, Kawai M, Niwa C, Kurosawa N, Matsuyama T, Yusoff FM, Toda T (2012) Maximum organic loading rate for the single-stage wet anaerobic digestion of food waste. Bioresour Technol 118:210-218

National Bureau of Statistics of China (2016) China statistical yearbook. China Statistics Press, Beijing

Procházka J, Dolejš P, Máca J, Dohányos M (2012) Stability and inhibition of anaerobic processes caused by insufficiency or excess of ammonia nitrogen. Appl Microbiol Biotechnol 93(1):439-447

Rajagopal R, Massé DI, Singh G (2013) A critical review on inhibition of anaerobic digestion process by excess ammonia. Bioresour Technol 143:632-647

Søndergaard MM, Fotidis IA, Kovalovszki A, Angelidaki I (2015) Anaerobic codigestion of agricultural byproducts with manure for enhanced biogas production. Energy Fuels 29(12):8088-8094

Song XY, Zhang KQ, Han BY, Liang JF, Zhai ZW, Du LZ (2016) Anaerobic co-digestion of pig manure with dried maize straw. BioResources 11(4):8914-8928

Sosnowski P, Wieczorek A, Ledakowicz S (2003) Anaerobic co-digestion of sewage sludge and organic fraction of municipal solid wastes. Adv Environ Res 7(3):609-616
Vavilin VA, Fernandez B, Palatsi J, Flotats X (2008) Hydrolysis kinetics in anaerobic degradation of particulate organic material: an overview. Waste Manag 28(6):939-951

Weiland P (2010) Biogas production: current state and perspectives. Appl Microbiol Biotechnol 85(4):849-860

Wu X, Yao WY, Zhu J, Miller C (2010) Biogas and $\mathrm{CH}_{4}$ productivity by codigesting swine manure with three crop residues as an external carbon source. Bioresour Technol 101(11):4042-4047

Zhang RH, Tao J, Dugba PN (2000) Evaluation of two-stage anaerobic sequencing batch reactor systems for animal wastewater treatment. Trans ASAE 43(6):1795-1801

Zhang RH, Elmashad HM, Hartman K, Wang F, Liu GQ, Choate C, Gamble P (2007) Characterization of food waste as feedstock for anaerobic digestion. Bioresour Technol 98(4):929-935

Zhao C, Yan H, Liu Y, Huang Y, Zhang RH, Chen C, Liu GQ (2016) Bio-energy conversion performance, biodegradability, and kinetic analysis of different fruit residues during discontinuous anaerobic digestion. Waste Manag 52:295-301

Zhu N, Ma J (2014) Changes and outlook about production amount of livestock and poultry manure in china. Agric Outlook 1:46-48

\section{Submit your manuscript to a SpringerOpen ${ }^{\circ}$ journal and benefit from:}

- Convenient online submission

- Rigorous peer review

- Open access: articles freely available online

- High visibility within the field

- Retaining the copyright to your article

Submit your next manuscript at $\boldsymbol{\nabla}$ springeropen.com 